\title{
EVOLUÇÃO DO BANCO DE SEMENTES DE ARROZ VERMELHO EM DIFERENTES SISTEMAS DE UTILIZAÇÃO DO SOLO DE VÁRZEAS ${ }^{1}$
}

\author{
LUIS A. DE AVILA ${ }^{2}$, ENIO MARCHEZAN ${ }^{3}$, SÉRGIO L. DE O. MACHADO ${ }^{4}$ RICARDO P. DA SILVA ${ }^{5}$
}

\section{RESUMO}

Num ecossistema agrícola, a redução do banco de sementes é um dos aspectos mais importantes no manejo de plantas daninhas; e em solos de várzeas, o arroz vermelho (Oryza sativa L.) é atualmente considerado a principal planta daninha. Nesse sentido, conduziu-se um experimento com o objetivo de avaliar a evolução do banco de sementes de arroz vermelho no solo em diferentes sistemas de semeadura de arroz irrigado e em alternativas de manejo do solo de várzea. $\mathrm{O}$ experimento foi instalado em campo por dois anos consecutivos na mesma área (safras agrícolas 1996/97 e 1997/98) em Santa Maria, RS, em solo classificado como Planossolo, com infestação média de 516 sementes viáveis de arroz vermelho/ $\mathrm{m}^{2}$. A estimativa do banco de sementes de arroz vermelho foi realizada através de 10 coletas de solo, utilizando um cilindro com $0,10 \mathrm{~m}$ de diâmetro a $0,10 \mathrm{~m}$ de profundidade. Após a coleta, os grãos foram separados do solo e realizado teste de tetrazólio para determinar a quantidade de sementes viáveis na amostra. As coletas foram realizadas antes da instalação do experimento (set/1996), após a colheita do primeiro ano (mai/1997) e após a colheita do segundo ano (mai/1998). Os resultados mostraram que o cultivo do arroz no sistema convencional promove aumento no banco de sementes de arroz vermelho, enquanto que a semeadura de arroz em solo inundado (mix de pré-germinado, prégerminado ou transplante de mudas) é tão eficiente na redução do banco de sementes de arroz vermelho quanto a rotação com o sorgo, o pousio do solo sem a presença de animais e também o preparo de verão.

Palavras chave: Planta daninha, rotação de culturas, dinâmica de populações, sistemas de cultivo, Oryza sativa.

\section{ABSTRACT \\ Red rice seed bank evolution under different systems of lowland utilization}

In an agricultural ecosystem, the redution of weed seed bank is of utmost importance. In lowland areas, red rice (Oryza sativa) is the most important weed. Therefore, an experiment was conducted to evaluate the evolution of the red rice seed bank under different seeding systems and alternatives of soil management. The experiment was conducted during two years (1996/97 and $1997 / 98$ growing seasons) in Santa Maria, RS in Albaqualf soil with an average infestation of 556 viable seeds per square meter. The assessement of the seed bank was conducted by ten samplings using a cylinder with $10 \mathrm{~cm}$ of diameter and $10 \mathrm{~cm}$ depth. After each sampling the seeds were separated and the number of viable seeds was determinated by tetrazolium test. The sampling were carried out before establishing the experiment (September 1996) after the first harvest (May 1997) and after the second harvest (May 1998).

\footnotetext{
${ }^{1}$ Recebido para publicação em 22/04/99 e na forma revisada em 05/05/2000. Parte da Dissertação de Mestrado em Agronomia do primeiro autor.

${ }^{2}$ Eng $^{\mathrm{o}}$ Agr $^{\mathrm{o}}$ MSc. Prof ${ }^{\mathrm{o}}$ Assistente, Dept ${ }^{\mathrm{o}}$ de Fitotecnia da Universidade Federal de Santa Maria (UFSM), Centro de Ciências Rurais, CEP: 97.105-900, Santa Maria/RS. Fone: (055) 220-8451. E-mail: laavila@ccr.ufsm.br.

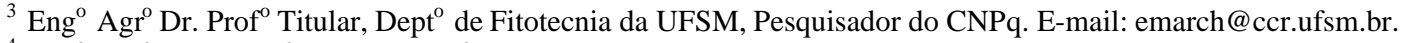

${ }^{4}$ Eng $^{\mathrm{O}}$ Agr $^{\mathrm{o}}$ MSc. Prof ${ }^{\mathrm{O}}$ Titular, Dept ${ }^{\mathrm{o}}$ de Defesa Fitossanitária da UFSM. E-mail: smachado@ @cr.ufsm.br.

5 Acadêmico do Curso de Agronomia da UFSM.
} 
The results showed that the traditional rice cropping method increases the red rice seed bank, whereas the systems in which the rice is seeded in flooded soil (no tillage water seeded, water seeded and transplanted seedlings) are as efficient in reducing the red rice seed bank as the system that

\section{INTRODUÇÃO}

No Rio Grande do Sul, o arroz vermelho é considerado a planta daninha que causa mais danos à lavoura orizícola em decorrência da redução de produtividade, da depreciação comercial do produto final, das dificuldades de controle e do alto grau de infestação das áreas cultivadas (Souza \& Fischer, 1986). Além disso, provoca elevação do custo de produção e deprecia o valor comercial das áreas cultivadas. Dentre as características principais do arroz vermelho, destaca-se o degrane precoce das sementes (Marchezan \& Cirolini, 1996) e sua longevidade no solo (Goss \& Brown, 1939; Noldin, 1995), podendo-se encontrar sementes viáveis no solo após um período de até nove anos (Goss \& Brown, 1939); tornando-se assim, o banco de sementes o fator principal no estabelecimento das estratégias de controle.

Nos agroecossistemas, a composição quantitativa e qualitativa da flora daninha reflete o sistema de cultivo em uso (Debaeke \& Sebilote, 1988), e é resultado do balanço entre entrada de novas sementes e perdas delas por germinação, deterioração, predação e transporte por vários agentes (Carmona, 1992).

Dentre os métodos de controle das plantas daninhas, o mais antigo e popular é o pousio do solo durante certo período, destacando-se aquele com preparo de solo durante o verão (Roberts \& Dawkins, 1967). O pousio do solo por um a dois anos, e a mobilização do solo através de gradagens reduz a quantidade de sementes de arroz vermelho no solo; pois com a mobilização do mesmo, as sementes encontram condições ambientais favoráveis para germinar e emergir podendo ser controladas três ou quatro populações de arroz applies crop rotation with sorghum or fallow without the presence of grazing animals or soil tillage during summer.

Key words: Weed, crop rotation, plant population dinamics, crop systems, Oryza sativa.

vermelho durante o período de primavera/verão (Huey \& Baldwin, 1978; Sonnier, 1978).

A rotação de culturas, principalmente com milho, sorgo e soja, associada ao uso de herbicidas de ação graminicida é uma alternativa utilizada em vários países para o controle de arroz vermelho (Sonnier, 1978; Smith Jr., 1989; Griffin \& Harger, 1990; Marchezan et al., 1995; Coradini et al., 1998), proporcionando além do controle do arroz vermelho, incrementos no rendimento do arroz cultivado na seqüência da rotação (Pauletto et al., 1991) e redução do banco de arroz vermelho (Marchezan et al., 1995; Coradini et al., 1998). Além destas culturas, a rotação pode ser realizada com pastagens cultivadas de verão ou de inverno (Marchezan, 1995).

Nas diversas regiões do mundo, o arroz irrigado é cultivado de forma bastante diferenciada, e os sistemas de cultivo constituem as principais alternativas usadas pelos produtores para o controle de arroz vermelho. Diversos autores (Petrini et al., 1993b; Bizzi, 1994; Petrini et al., 1996; Andres et al., 1997; Machado et al., 1998; Silva et al., 1998) mencionam que a semeadura do arroz em solo inundado como o sistema pré-germinado, mix de pré-germinado e o transplante de mudas reduzem o banco de sementes de arroz vermelho.

O sistema de semeadura direta é outra alternativa muito utilizada pelos produtores do Rio Grande do Sul no controle do arroz vermelho. O desenvolvimento deste sistema possibilitou a reutilização de áreas já abandonadas para o cultivo do arroz, em decorrência de altas infestações de arroz vermelho que aí se desenvolveram (Oliveira, 1993; Bizzi, 1994). Entretanto, deve-se enfatizar que em anos com adversidade climática durante a emergência do arroz, o controle de arroz 
vermelho é menor (Andres et al., 1997), podendo inclusive ocorrer aumento no banco de sementes (Machado et al., 1998).

Com base nestes pressupostos, o objetivo deste trabalho foi avaliar a evolução do banco de sementes de arroz vermelho em solo de várzeas submetido a diversos sistemas de cultivo na implantação da lavoura de arroz irrigado e de outras alternativas de manejo, como a rotação de culturas com sorgo ou com pastagem nativa, e suas conseqüências na dinâmica do banco de sementes.

\section{MATERIAL E MÉTODOS}

O experimento foi conduzido em área de várzea no Campus da Universidade Federal de Santa Maria, em solo classificado como Planossolo, pertencente à unidade de mapeamento Vacacaí, com infestação média de 516 (402-893) sementes viáveis de arroz vermelho/ $\mathrm{m}^{2}$; em área que se encontrava em pousio há um ano, após vários anos de cultivos de arroz irrigado. $\mathrm{O}$ delineamento experimental utilizado foi o de blocos ao acaso com quatro repetições no primeiro ano e três no segundo. Os tratamentos encontram-se descritos na Tabela 1. O solo foi preparado em setembro de 1996, através de uma gradagem pesada e duas de nivelamento, seguido de aplainamento superficial, quando foram demarcadas as parcelas (8 x 6m).

TABELA 1. Tratamentos para o controle do arroz vermelho, utilizados em cada ano de execução do experimento. Santa Maria, RS. 1999.

\begin{tabular}{|c|c|c|}
\hline \multirow{2}{*}{ Tratamentos e descrição } & \multicolumn{2}{|c|}{ Ano agrícola } \\
\hline & $1996 / 97$ & $1997 / 98$ \\
\hline [T1] - Arroz - semeadura convencional; & $*$ & ** \\
\hline $\begin{array}{l}\text { [T2] - Arroz - semeadura convencional, antecedida da aspersão e incorporação } \\
\text { de molinate }(5,75 \mathrm{~kg} / \mathrm{ha}) \text { no dia da semeadura e as sementes do arroz } \\
\text { protegidas por anidrido naftálico }(0,5 \% \text { v./v. }) \text {; }\end{array}$ & $*$ & ni \\
\hline $\begin{array}{l}\text { [T3] - Arroz - semeadura convencional, antecedido da aspersão e incorporação } \\
\text { de 2,4-D amina }(8,64 \mathrm{~kg} / \mathrm{ha}) 25 \text { dias antes da semeadura; }\end{array}$ & $*$ & ni \\
\hline [T4] - Arroz - cultivo mínimo no primeiro ano e semeadura direta no segundo; & $*$ & $* *$ \\
\hline $\begin{array}{l}\text { [T5] - Arroz - Mix de pré-germinado: semeadura com sementes pré-germinadas } \\
\text { em área preparada para o cultivo mínimo; }\end{array}$ & $*$ & $* *$ \\
\hline [T6] - Arroz - sistema de transplante de mudas; & ni & $* *$ \\
\hline [T7] - Arroz - sistema pré-germinado; & ni & $* *$ \\
\hline $\begin{array}{l}\text { [T8] - Arroz - semeadura direta, com roguing para retirada das plantas de arroz } \\
\text { vermelho; }\end{array}$ & ni & ** \\
\hline $\begin{array}{l}\text { [T9] - Pousio do solo, sem a presença de animais na área, e com simulação de } \\
\text { pastejo (roçadas semanais); }\end{array}$ & $*$ & $* *$ \\
\hline $\begin{array}{l}\text { [T10] - Sorgo no sistema de cultivo mínimo, com aspersão de atrazine }(2,25 \mathrm{~kg} / \mathrm{ha}) \\
\text { em pós-emergência precoce (arroz vermelho no estádio de duas a três } \\
\text { folhas); }\end{array}$ & $*$ & ** \\
\hline $\begin{array}{l}\text { [T11] - Preparo do solo durante o verão (três preparos por safra) com auxílio de } \\
\text { enxada rotativa autopropelida, a } 0,10 \mathrm{~m} \text { de profundidade }\end{array}$ & $*$ & ** \\
\hline
\end{tabular}

* Quatro repetições;

** Três repetições, uma repetição foi perdida devido a ocorrência de chuvas pesadas, durante o período de emergência; ni = não instalado. 
No primeiro ano, o tratamento [T4] foi instalado no sistema de cultivo mínimo, pois após o preparo do solo, deixou-se emergir as plantas daninhas, efetuando-se 12 dias antes da semeadura, a dessecação das mesmas. No segundo ano, foi instalado no sistema de semeadura direta, pois, após a colheita do arroz no primeiro ano, foi realizada semeadura a lanço de azevém, que produziu cerca de $1.500 \mathrm{~kg} / \mathrm{ha}$ de matéria seca, e que foi dessecado 15 dias antes da semeadura do arroz.

Nos tratamentos com o cultivo mínimo de arroz, mix de pré-germinado e também para o cultivo mínimo de sorgo, as plantas foram dessecadas através da aspersão do herbicida glyphosate $(1,25 \mathrm{~kg} / \mathrm{ha})$ acrescido de óleo mineral (0,5\% v./v.). Nos sistemas de cultivo mínimo e naquele com preparo convencional do solo, o controle de plantas daninhas foi realizado através da aspersão da mistura dos herbicidas propanil $(1,08 \mathrm{~kg} / \mathrm{ha})$ com clomazone $(0,25 \mathrm{~kg} / \mathrm{ha})$; e nos tratamentos com semeadura em solo inundado, pela aspersão da mistura de pyrazosulfuron-etil $(0,015 \quad \mathrm{~kg} / \mathrm{ha}) \quad$ com metsulfuron-metyl $(0,0024 \mathrm{~kg} / \mathrm{ha})$. Para a aplicação dos herbicidas foi utilizado pulverizador costal de precisão, pressurizado com $\mathrm{CO}_{2}$, com consumo de calda correspondendo a 80 litros/ha.

No primeiro ano, a semeadura de arroz foi realizada no dia 24/12/1996 utilizando-se a cultivar 'IRGA 416', de ciclo precoce; e no segundo ano, em 10/12/1997, usando-se a cultivar reagente 'IRGA 417', de ciclo médio.

Nos sistemas de semeadura em solo seco (T1, T2, T3, T4 e T8), foi utilizada uma semeadora-adubadora para plantio direto, com espaçamento de $0,18 \mathrm{~m}$ entre fileiras e na densidade de $200 \mathrm{~kg}$ de sementes/ha; enquanto que no sistema com sementes pré-germinadas, a semeadura foi realizada a lanço, na densidade de $120 \mathrm{~kg}$ de sementes/ha com o objetivo de obter-se 300 plantas $/ \mathrm{m}^{2}$. O transplante de mudas [ $\mathrm{T}_{6}$ ] foi realizado quando as plântulas de arroz atingiram o estádio de duas a três folhas desenvolvidas, espaçadas de $0,30 \mathrm{~m}$ entre fileiras e $0,12 \mathrm{~m}$ entre covas, na densidade de oito a 10 plantas de arroz por cova.

O manejo da água de irrigação foi diferente nos diferentes sistemas de cultivo de arroz. Nos tratamentos em que a semeadura foi realizada em solo seco, a entrada da água iniciou aos 25 dias, com uma lâmina de aproximadamente $80 \mathrm{~mm}$; permanecendo na área até a maturação fisiológica do arroz. No primeiro ano, para a semeadura em solo alagado (mix de prégerminado), a entrada da água foi realizada cinco dias antes da semeadura do arroz e a dessecação foi realizada aos cinco dias antes da entrada da água nas parcelas. No segundo ano, para os tratamentos com semeadura em solo inundado (T5, T6 e T7), a irrigação foi realizada 25 dias antes da semeadura e a dessecação foi realizada 20 dias antes da inundação das parcelas.

Para a semeadura do sorgo foram utilizados os híbridos $A G 2005$ e $A G$ 2006, respectivamente no primeiro e segundo ano de cultivo; na densidade de 16 sementes/m linear em espaçamento de $0,45 \mathrm{~m}$ entre fileiras.

No tratamento com pousio da área foi realizada simulação de pastejo através de roçadeira manual em intervalos semanais.

Para a avaliação do banco de sementes, fez-se amostragem (coleta) de solo antes da instalação do experimento (nov/96), após a colheita do primeiro ano (mai/97) e também após a colheita do segundo ano (mai/98). Através destas avaliações, estimouse a evolução do banco de sementes de arroz vermelho para cada tratamento.

A coleta de solo foi realizada na profundidade de $0-10 \mathrm{~cm}$ com auxílio de um trado de $10 \mathrm{~cm}$ de diâmetro, através de 10 amostras por parcela. Após a coleta, as amostras foram lavadas em água corrente e peneiradas (malha $=2 \mathrm{~mm}$ ) para a separação das sementes de arroz vermelho do solo. Após, as sementes foram secas e levadas ao laboratório onde foram submetidas ao teste de tetrazólio.

No segundo ano, em cada parcela, foram fixados em estacas de madeira, cinco copos de plástico $(0,085 \mathrm{~cm}$ de diâmetro $)$ a $0,15 \mathrm{~m}$ de altura do solo 
com a finalidade de estimar-se o número de sementes de arroz vermelho degranadas.

Em cada parcela foi realizado o monitoramento, calculando-se a quantidade de sementes de arroz vermelho encontradas no solo após a colheita do arroz cultivado em relação ao número inicial de sementes de arroz vermelho contida no solo, através da fórmula:

Percentual de sementes em relação ao nível inicial $=\left(\mathrm{N}_{\text {sap }} * 100\right) / \mathrm{N}_{\text {sant }}$, onde:

$\mathrm{N}_{\text {sap }}=$ número de sementes de arroz vermelho encontradas no solo após a colheita do experimento

$\mathrm{N}_{\text {sant }}=$ número de sementes de arroz vermelho antes da instalação do experimento.

No segundo ano, o cálculo descrito acima foi feito de duas formas, tomando-se como base o banco de sementes do ano anterior (1997) e tomando-se como base o primeiro ano (1996), para verificar o efeito de dois anos. Além desta determinação estimou-se: a) Banco de sementes esperado após a colheita (1998): $\mathbf{B}_{\text {esp }}=\mathbf{B}_{\text {antes97 }}+$ Degrane $_{98}$, onde: $\mathbf{B}_{\text {antes } 97}=$ número de sementes viáveis de arroz vermelho presentes no solo antes da instalação do experimento (mai/97) e Degrane $_{98}=$ número de sementes viáveis de arroz vermelho degranadas durante o ciclo do arroz coletadas nos copos plásticos; b) Número de sementes que saíram do banco de sementes, através da fórmula: Decréscimo de Sementes $_{\text {BS }}=\mathbf{B}_{\text {esp }}-$ Ban $_{\text {sem98, }}$ onde $\mathbf{B}_{\text {esp }}=$ banco de sementes esperado e $\mathbf{B a n}_{\text {sem } 98}=$ banco de sementes após a colheita de 1998 (mai/98); c) Número de sementes remanescentes do ano anterior: Sementes remanescentes $=\mathbf{B a n}_{\text {sem98 }}$ Degrane.

Os dados foram submetidos à análise da variância e as médias comparadas entre si pelo teste de Duncan $(\mathrm{p} \leq 0,05)$. Para o cálculo da percentagem de decréscimo de sementes do banco foi realizada a análise por grupamento com teste de Scheffé $(\mathrm{p} \leq 0,05)$. Para fins de normalização de sua distribuição, antes da análise da variância, os dados em percentagem foram transformados em arc. sen $\sqrt{\%+0,5 / 100}$ e os do número de sementes de arroz vermelho/ $\mathrm{m}^{2}$ e de degrane de sementes $/ \mathrm{m}^{2}$ em $\sqrt{x+0,5}$.

\section{RESULTADOS E DISCUSSÃO}

Na Tabela 2 verifica-se que os tratamentos que proporcionaram redução do banco de sementes no primeiro ano (1996/97) foram o cultivo mínimo de arroz, o mix de pré-germinado de arroz, o pousio do solo, o cultivo de sorgo e o preparo do solo durante o verão, em 22, 37, 79, 90 e $90 \%$, respectivamente. Os demais tratamentos $\left(\mathrm{T}_{1}, \mathrm{~T}_{2}\right.$ e $\left.\mathrm{T}_{3}\right)$ resultaram em aumento no banco de sementes, na ordem de 246, 124 e 89\%, respectivamente.

A redução do banco de sementes no sistema de cultivo mínimo ocorreu, provavelmente pelo melhor controle do arroz vermelho, com pouca contribuição para o banco de sementes neste ano, e pela permanência das sementes de arroz vermelho na superfície do solo, ficando mais sujeitas às condições climáticas e biológicas, que proporcionam decréscimo mais rápido das sementes de arroz vermelho do solo (Noldin, 1995). Já, no segundo ano (1997/98), o sistema de semeadura convencional e o sistema de semeadura direta, proporcionaram aumento do banco de sementes, em 451 e $341 \%$, respectivamente. Os sistemas de semeadura em solo inundado (mix, transplante e pré-germinado), reduziram em 13, 85 e $88 \%$ e o roguing, pousio do solo, sorgo e preparo de verão, com redução de 52, 100, 100 e 100\%, respectivamente.

A diferença do comportamento da evolução do banco de sementes no sistema de semeadura direta ou cultivo mínimo, em que no primeiro ano ocorreu redução e no segundo ano aumento do banco de sementes, confirma que a eficiência no controle do arroz vermelho pelo sistema de semeadura direta ou cultivo mínimo é dependente do manejo empregado na cultura (Machado et al., 1998), e das condições climáticas no período de emergência do arroz (Andres et al., 1997). 
TABELA 2. Número de sementes viáveis arroz vermelho no solo, número de sementes degranadas durante o ciclo da cultura (1997/98), número de grãos de arroz vermelho e percentual de sementes viáveis encontradas no solo após a estação de crescimento. Santa Maria, RS.

\begin{tabular}{|c|c|c|c|c|c|c|c|c|c|}
\hline \multirow[t]{3}{*}{ Tratamentos } & \multicolumn{4}{|c|}{ Sementes viáveis $/ \mathrm{m}^{2}$} & \multicolumn{2}{|c|}{$\begin{array}{l}\text { Grãos de arroz } \\
\text { vermelho/m² }\end{array}$} & \multicolumn{3}{|c|}{$\begin{array}{l}\text { Percentual de sementes viáveis } \\
\text { encontradas no solo após a estação de } \\
\text { crescimento em relação aos níveis } \\
\text { iniciais no solo }\end{array}$} \\
\hline & & No solo & & Degrane & & & & & \\
\hline & Nov. 1996 & Maio 1997 & Maio 1998 & durante ciclo 97/98 & Nov. 1996 & Maio 1998 & $1996 / 97^{2}$ & $1997 / 98^{3}$ & $1996 / 98^{4}$ \\
\hline [T1] Convencional & $402^{\mathrm{ns}}$ & $919 b c^{1}$ & $4.345 \mathrm{a}$ & $4.071 \mathrm{a}$ & $836^{\mathrm{ns}}$ & $5.558 \mathrm{a}$ & 346 a & $551 \mathrm{a}$ & $690 \mathrm{a}$ \\
\hline [T2] Molinate & 454 & - & - & - & - & - & $224 a b$ & - & - \\
\hline [T3] 2,4-D & 555 & - & - & - & - & - & $189 \mathrm{ab}$ & - & - \\
\hline [T4] Mínimo/Direto & 893 & $285 \mathrm{c}$ & $1.410 \mathrm{~b}$ & $1.266 \mathrm{~b}$ & 545 & $2.374 \mathrm{ab}$ & $78 \mathrm{bc}$ & $441 \mathrm{~b}$ & $338 \mathrm{~b}$ \\
\hline [T5] Mix & 416 & $184 \mathrm{c}$ & $159 \mathrm{bc}$ & $124 \mathrm{bc}$ & 783 & $348 \mathrm{bc}$ & $63 \mathrm{bc}$ & $87 \mathrm{bc}$ & $38 \mathrm{c}$ \\
\hline [T6] Transplante & - & $3.616 \mathrm{a}$ & $389 \mathrm{bc}$ & $115 \mathrm{c}$ & - & - & - & $15 \mathrm{c}$ & - \\
\hline [T7] Pré-germinado & - & $2.471 \mathrm{ab}$ & $210 \mathrm{bc}$ & $68 c$ & - & - & - & $12 \mathrm{c}$ & - \\
\hline [T8] Roguing & - & $612 b c$ & $172 b c$ & $0 \mathrm{c}$ & - & - & - & $48 \mathrm{c}$ & - \\
\hline [T9] Pousio & 538 & $110 \mathrm{c}$ & $0 \mathrm{c}$ & $0 \mathrm{c}$ & 987 & $97 \mathrm{c}$ & $21 \mathrm{c}$ & $0 \mathrm{c}$ & $0 \mathrm{c}$ \\
\hline [T10] Sorgo & 441 & $16 \mathrm{c}$ & $0 \mathrm{c}$ & $0 \mathrm{c}$ & 488 & $8 \mathrm{c}$ & $10 \mathrm{c}$ & $0 \mathrm{c}$ & $0 \mathrm{c}$ \\
\hline [T11] Preparo & 432 & $13 \mathrm{c}$ & $0 \mathrm{c}$ & $0 \mathrm{c}$ & 443 & $4 \mathrm{c}$ & $10 \mathrm{c}$ & $0 \mathrm{c}$ & $0 \mathrm{c}$ \\
\hline Média & 516 & 914 & 725 & 627 & 680 & 1.398 & 118 & 128 & 118 \\
\hline $\mathrm{CV}(\%)$ & 41,4 & 57,1 & 79,8 & 92,0 & 36,3 & 71,5 & 52,7 & 36,8 & 35,8 \\
\hline
\end{tabular}

${ }^{\text {ns }}$ Não significativo pelo teste $\mathrm{F}$ a nível de $5 \%$ de probabilidade.

Médias não seguidas por mesma letra, diferem entre si pelo teste de Duncan. $(P \leq 0,05)$

${ }^{2}$ Tomado o banco de sementes de 1996 como $100 \%$

Tomado o banco de sementes de 1997 como 100\%

Tomado o banco de sementes de 1996 como $100 \%$ 
A redução do banco de sementes promovida pelos tratamentos de semeadura de arroz com sementes pré-germinadas e com o transplante de mudas, confirma resultados obtidos por Machado et al. (1998) e Silva et al. (1998), que verificaram maior eficiência do sistema de semeadura com sementes pré-germinadas na redução da infestação de sementes de arroz vermelho no solo.

Após dois anos de cultivo na mesma área (1996 - 1998) a semeadura no sistema convencional e a semeadura direta promoveram acréscimos no banco de sementes de arroz vermelho na ordem de $590 \%$ e $238 \%$. O mix de pré-germinado reduziu o banco de sementes, restando apenas $38 \%$ da quantidade inicial. Nos tratamentos alternativos ao arroz irrigado (pousio do solo " $\mathrm{T}_{9}$ ", cultivo com sorgo " $\mathrm{T}_{10}$ " e preparo de verão " $\mathrm{T}_{11}$ "), apesar de se encontrar alguns grãos de arroz vermelho no solo (Tabela 2), os mesmos não eram viáveis. Assim, nos sistemas alternativos ao cultivo do arroz houve redução de $100 \%$ das sementes viáveis de arroz vermelho do banco de sementes.

O sistema mix de pré-germinado, com redução de $37 \%$ no primeiro ano, $14 \%$ no segundo ano e $51 \%$ no total dos dois anos é um sistema de semeadura de arroz irrigado que tem boa eficiência no controle do banco de sementes de arroz vermelho e é uma alternativa viável para semeadura de arroz irrigado com sementes prégerminadas em lavouras de maior porte. Porém, faz-se necessário mais estudos com respeito à qualidade e quantidade de massa seca de cobertura sobre o estabelecimento da cultura neste sistema de cultivo.

A redução "total" do banco de sementes nos tratamentos alternativos ao arroz (pousio, sorgo e preparo de verão), após dois anos de execução do experimento, pode não ser totalmente verdadeira, pois pode ter sobrado sementes no solo em pequena quantidade que não foram detectadas pelo método de amostragem utilizado. Ball \& Miller (1989), observaram que devido à pequena área de solo amostrada em comparação com a área total da parcela, sementes presentes em número reduzido no solo podem não ser detectadas durante a amostragem.

Estes dados são contrastantes com relatos de literatura, onde foi constatada a viabilidade das sementes de arroz vermelho por mais de nove anos (Goss \& Brown, 1939). Em trabalho mais recente, Noldin (1995), verificou que a sobrevivência destas sementes foi bem menor, em torno de 17 meses, quando localizadas na superfície do solo. Uma possível explicação, para este fato é a afirmação de Harlan (1965), de que as plantas daninhas evoluem em paralelo com as cultivadas; considerando-se que a taxa de cruzamento do arroz cultivado com o arroz vermelho é significativa, variando de 1 a $52 \%$; e tanto maior quanto maior for a semelhança de ciclo entre a cultivar de arroz e os biótipos de arroz vermelho (Langevin et al., 1990). Então a redução do período de dormência do arroz vermelho pode ser uma destas características de evolução.

A redução do banco de sementes na rotação de culturas e no pousio do solo verificado neste trabalho, também foi verificada por outros autores (Marchezan et al., 1995; Coradini et al., 1998) e corroboram com os resultados apresentados por Noldin (1995), em que a manutenção das sementes de arroz vermelho na superfície do solo favorece a perda de viabilidade das sementes. Por outro lado, o preparo do solo durante o verão também proporcionou redução do banco de sementes, semelhante àquela proporcionada pela rotação de culturas e pelo pousio do solo. Esta redução confirma os resultados de Huey \& Baldwin (1978).

A quantidade de sementes de arroz vermelho que saíram do banco de sementes, e das sementes remanescentes do ano anterior, em valores absolutos, não dão idéia do efeito dos tratamentos sobre estes parâmetros, visto que as quantidades iniciais de sementes viáveis de arroz vermelho no solo são diferentes entre os tratamentos. Assim, foi calculado a composição do banco de sementes de arroz vermelho em percentagem (Figuras 1 e 2). 


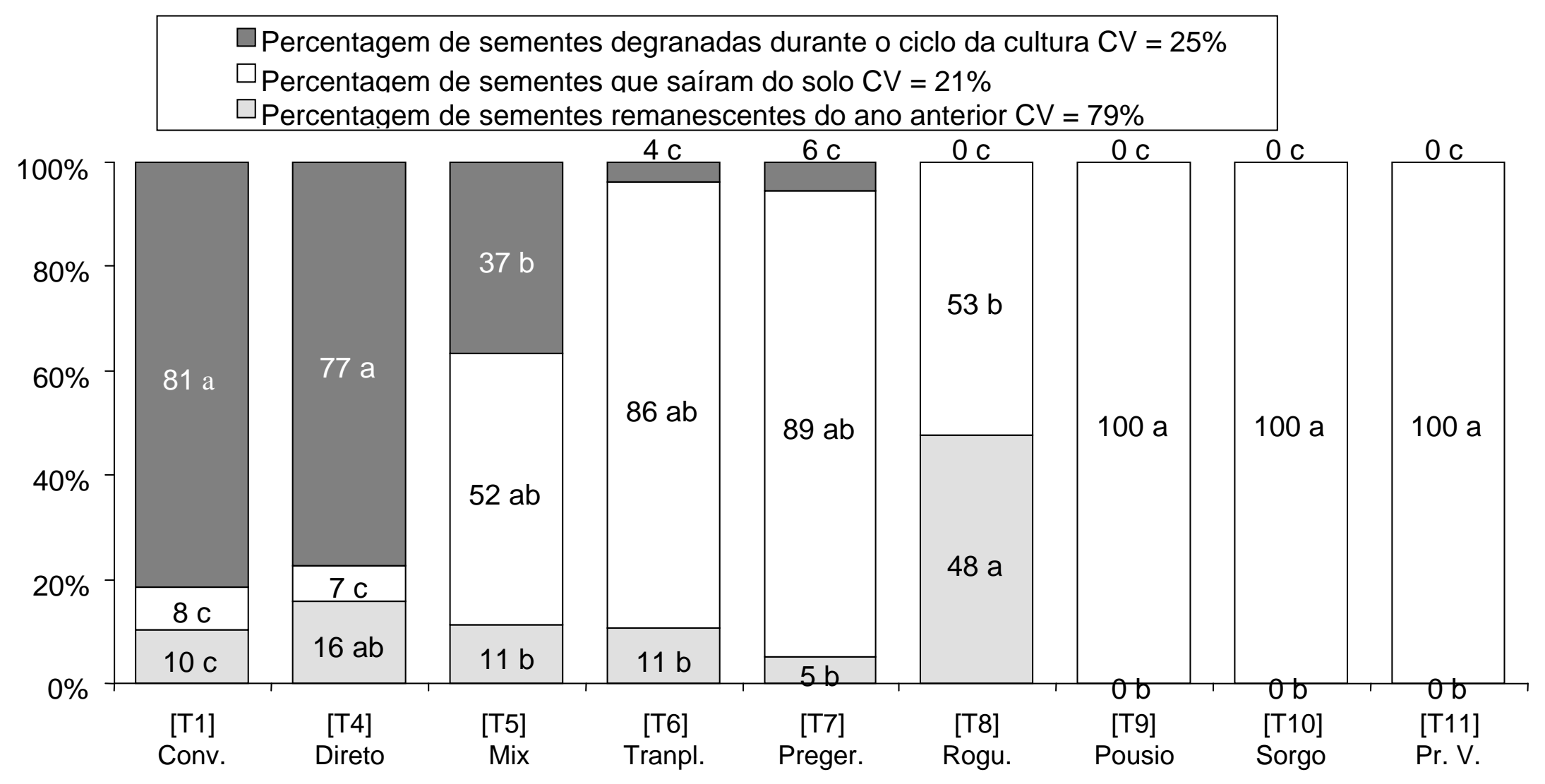

Médias não ligadas pela mesma letra diferem entre si pelo teste de Duncan ao nível de 5\% de probabilidade $(P \leq 0,05)$.

FIGURA 1. Composição do banco de sementes viáveis de arroz vermelho com relação a percentagem de degrane, de sementes que deixaram o banco de sementes e de sementes remanescentes do ano anterior (Safra agrícola 1997/98). Santa Maria, RS. 1999. 


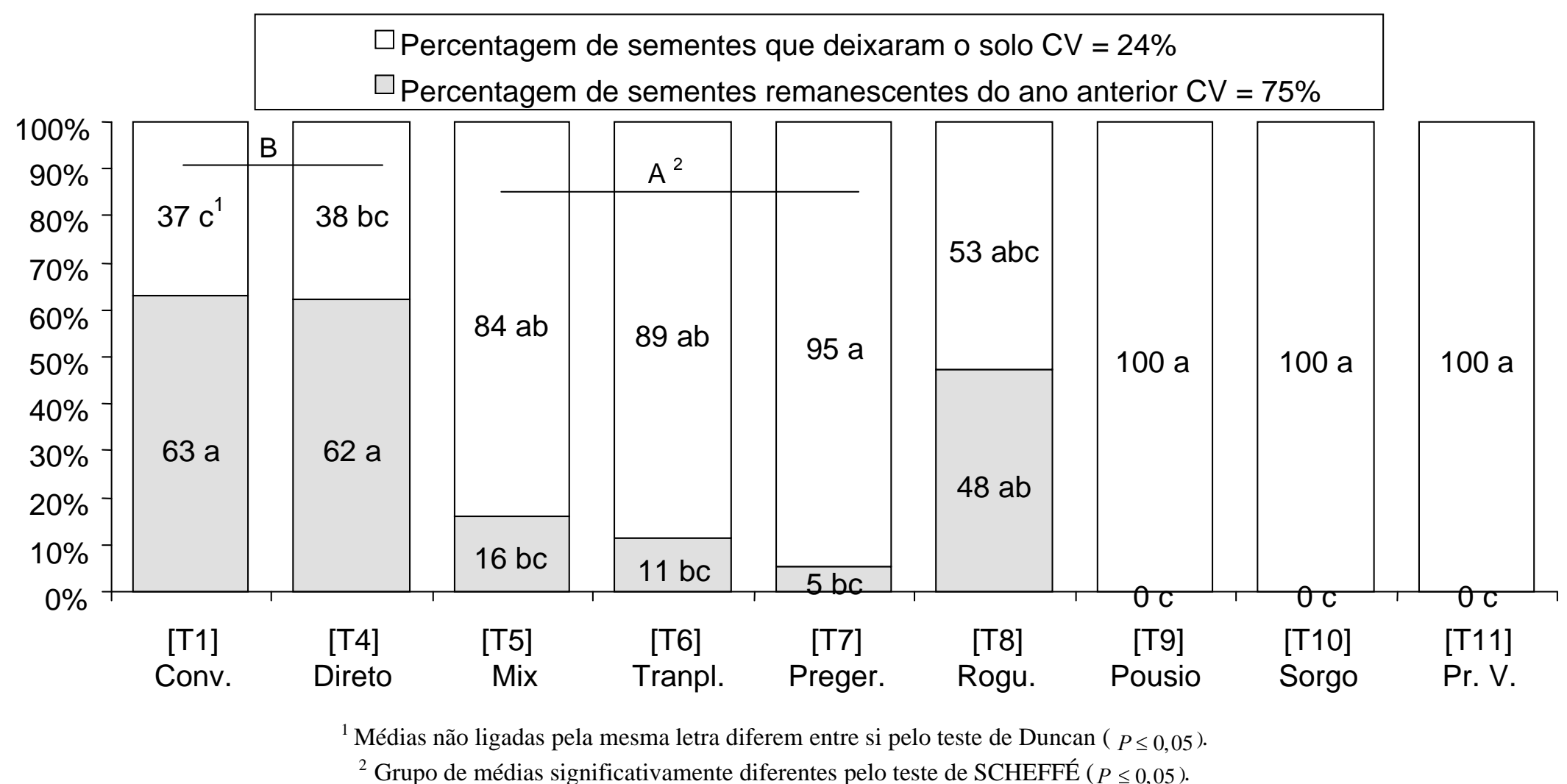

FIGURA 2. Composição do banco de sementes viáveis de arroz vermelho, com relação a percentagem de sementes que deixaram o banco de sementes e de sementes remanescentes do ano anterior (Safra agrícola 1997/98). Santa Maria, RS. 1999. 
Na Figura 1 é apresentado o percentual de sementes degranadas durante o ciclo da cultura, de sementes que saíram do solo por algum motivo (mortas, emergidas durante a pré-semeadura ou ciclo da cultura, consumidas por animais, entre outras causas) e de sementes remanescentes do ano anterior (aquelas que mantiveram-se por uma safra no solo). Já na Figura 2, para melhor avaliar o percentual de sementes que saíram do banco de sementes, retirou-se os dados de degrane.

Na Figura 1, verifica-se que no sistema de semeadura convencional e na semeadura direta a maior parte das sementes do banco de sementes foi proveniente do degrane durante a estação de crescimento do arroz. Esta contribuiu com $81 \%$ no sistema convencional e $77 \%$ na semeadura direta. Isto demonstra a capacidade de manutenção da infestação nestes sistemas de cultivo e o baixo controle do arroz vermelho, confirmando os resultados encontrados por outros autores (Andres et al., 1997; Silva et al., 1998). Estes resultados servem de subsídio na decisão do manejo utilizado em área de semeadura de arroz irrigado no sistema de plantio direto e cultivo mínimo. Baseando-se nos dados de Rota (1993), Petrini et al. (1993a), Noldin (1995) e de Petrini et al. (1998), o melhor manejo pós-colheita a ser utilizado nesta área é a não mobilização do solo, para não incorporar este percentual significativo de sementes ao solo e sim deixá-las na superfície para que percam viabilidade mais rapidamente.

A ocorrência de algumas plantas de arroz vermelho nos sistemas de cultivo de arroz irrigado com inundação prévia (mix de pré-germinado, transplante de mudas e e sistema pré-germinado), com conseqüente degrane de sementes para o solo (Tabela 2), concordam com Eberhardt et al. (1997), que afirmaram que a presença de lâmina de água não é fator totalmente limitante à emergência das sementes de arroz vermelho. Outros fatores, como a localização das sementes no perfil do solo e a altura da lâmina de água influem na emergência desta planta daninha. Os autores citados verificaram, ainda, que com lâmina de água de $5 \mathrm{~cm}$ de altura, ocorreu emergência de
$46 \%$ das sementes de arroz vermelho localizadas na superfície do solo.

Nos tratamentos de pousio do solo, sorgo e preparo de verão, a contribuição de novas sementes de arroz vermelho para o solo (degrane) foi evitada (Tabela 2). No pousio do solo as plantas de arroz vermelho emergidas foram controladas pela simulação de pastejo (roçadas), na cultura do sorgo a aplicação do herbicida atrazine foi suficiente para controlar $100 \%$ das plantas de arroz vermelho e no preparo de verão as plantas foram controladas pela ação do preparo do solo. O excelente controle do arroz vermelho, obtido com o cultivo do sorgo, confirma os dados de Huey \& Ford (1978) que obtiveram controle de $100 \%$ do arroz vermelho com aplicação de atrazine em pós emergência inicial, nesta cultura.

Nos tratamentos com semeadura em solo inundado (mix de pré-germinado, transplante de mudas e pré-germinado) a maior proporção foi de sementes que deixaram o banco de sementes (Figura 2), como foi verificado através do resultado do teste de Scheffé, em que os três sistemas de cultivo em solo inundado (T5, T6 e T7) foram contrastados com os dois sistemas de semeadura em solo seco (convencional e direto).

A maior percentagem de sementes que deixaram o banco de sementes do solo verificada nos sistemas com semeadura em solo inundado (Figura 2), foi devido provavelmente, ao maior período de inundação do solo, pois no sistema de semeadura de arroz em solo seco a inundação do solo foi realizada cerca de 25 dias após a emergência do arroz, enquanto nos sistemas com semeadura em solo inundado, a inundação foi realizada em torno de 25 dias antes da semeadura ou transplante, proporcionando maior período de inundação (50 dias), com conseqüente ampliação do período de deficiência de oxigênio. A perda de viabilidade das sementes de arroz vermelho submetidas a inundação foi também verificada por Petrini et al. (1993b) e ocorre em função da anoxia (deficiência de oxigênio), que é prejudicial a algumas espécies (Taylorson, 1987). Isto deve-se ao incremento na rota metabólica via glicolítica, 
promovendo a formação de lactato e etanol, que são prejudiciais à viabilidade de inúmeras espécies (Crawford, 1977).

A dormência das sementes é uma forma de proteção contra adversidades ambientais, sendo que sementes de inúmeras espécies tem esta habilidade quando algum fator ambiental torna-se limitante ou prejudicial à perpetuação da espécie (Carmona, 1992), como é o caso da deficiência de oxigênio causada pela inundação. Por outro lado, sabe-se que em solos inundados ocorre aumento na formação de etileno chegando a níveis de 20ppm (Smith \& Restall, 1971), que age na quebra de dormência de sementes de espécies daninhas (Egley \& Dale, 1970; Saini et al., 1986).

É possível que o etileno também atue sobre o arroz vermelho, pois sobre o arroz cultivado foi verificado esse efeito (Bertagnolli, et $a l .$, 1997), favorecendo a superação da dormência de suas sementes, submetendo-as aos efeitos da deficiência de oxigênio, podendo levá-las à perda de viabilidade. Alguns autores não têm verificado este efeito (Roberts, 1963; Sikder, 1967), mas no solo pode ocorrer interações com outros fatores que podem resultar na potencialização deste efeito.

\section{LITERATURA CITADA}

ANDRES, A., LEITÃO, E., MENEZES, V. G. et al. Controle de arroz vermelho em sistemas de cultivo de arroz irrigado. In: REUNIÃO DA CULTURA DO ARROZ IRRIGADO, 22., 1997, Balneário Camboriú, SC. Anais ... Itajaí: EPAGRI, 1997. 580p., p.418-420.

BALL, D.A., MILLER, S.D. A comparison of techniques for estimation of arable soil seedbanks and their relationship to weed flora. Weed Res., v. 29, p. 365-373, 1989.

BERTAGNOLLI, C. H., MENEZES, N. L., BRACKMANN, A. et al. Efeito de concentrações de etileno sobre a superação da dormência de sementes de arroz cv. Yerbal. In: JORNADA INTEGRADA DE
PESQUISA, EXTENSÃO E ENSINO, 4., Santa Maria, RS. 1997. Anais ... Santa Maria:UFSM, 1997, p.570.

BIZZI, F. A. Alternativas de controle do arroz vermelho e capim arroz na cultura do arroz irrigado. Santa Maria: UFSM, 1994. 80p. Dissertação (Mestrado em Agronomia) - Universidade Federal de Santa Maria, 1994.

CARMONA, R. Problemática e manejo de bancos de sementes de invasoras em solos agrícolas. Planta Daninha, v.40, n.12, p.5-16, 1992.

CORADINI, J. Z., ANDRES, A., AVILA, L. A. de. et al. Rotação de culturas e pousio do solo reduzem o banco de sementes de arroz vermelho (Oryza sativa L.) em solo de várzea. In: SALÃO DE INICIAÇÃ̃ CIENTÍFICA 10., e FEIRA DE INICIAÇÃO CIENTÍFICA, 4. 1998, Porto Alegre. Livro de Resumos ... Porto Alegre: UFRGS, 1998, 503p., p. 127.

CRAWFORD, R. M. M. Tolerance of anoxia and ethanol metabolism in germinating seeds. New Phytol. v.79, p.511-517, 1977.

DEBAEKE, P., SEBILLOTE, M. Modelisation de lo'evolution à long terme de la flore adventice. I. Constrution d'un modéle descriptif de l'évolution quantitative du stock de semences a l'horizon travaillé. Agronomie, v.8, n.5, p.393-403,1988.

EBERHARDT, D. S., SILVA, P. R. F., PEDROSO, M. et al. Emergência e desenvolvimento inicial de arroz e de plantas daninhas em função da profundidade da semente e submersão do solo. In: REUNIÃO DA CULTURA DO ARROZ IRRIGADO, 22., 1997, Balneário Camboriú, SC. Anais ... Itajaí: EPAGRI, 1997. 580p. p.387-390. 
EGLEY, G. H., DALE, J. E. Ethylene, 2chlorethyl-phosphonic acid, and witch weed germination. Weed Sci., v.18, p.586-589, 1970.

GRIFFIN, J.L., HARGER, T.J. Red rice (Oryza sativa) control options in soybeans (Glycine max). Weed Tecnol., v.4, p.35-38, 1990.

GOSS, W. L., BROWN, E. Buried red rice seed. J. Am. Soc. Agron, v.31, n.7, p.633-637, 1939.

HARLAN, J. R. The possible role of weed races in the evolution of cultivated plants. Euphytica, v. 14 , p. 173-176, 1965.

HUEY, B. A., BALDWIN, F. L. Red Rice control. In: RED RICE RESEARCH AND CONTROL. 1978, Beaumont. Procedings ... Beaumont: Texas A \& M University, 1978. 46p. p.19-25.

HUEY, B. A., FORD, L. Red rice control. In: RED RICE SYMPOSIUM HELD AT TEXAS A\&M UNIVERSITY, 1978, Texas. Procedings ... Texas, 1978.

LANGEVIN, A.S., CLAY, K. GRACE, J.B. The incidence and effects of hybridization between cultivated rice and its related weed rice (Oryza sativa L.). Evolution, v. 44, n.4, p.1000-1008, 1990.

MACHADO, S. L. de O., KUMMER, H., MAINARDI, A. A. B. et al. Arroz vermelho: Levantamento do banco de sementes e potencial de infestação em lavouras comerciais de arroz irrigado da Depressão Central do Rio Grande do Sul. In: REUNIÃO NACIONAL DE PESQUISA DE ARROZ. 6., 1998, Goiânia, GO. Perspectivas para a cultura do arroz nos ecossistemas de várzeas e terras baixas. Goiânia:
EMBRAPA-CNPAF, 1998. 514p, p.384-386. (EMBRAPA-CNPAF. Documentos, 85).

MARCHEZAN, E. Rotação de culturas em áreas de arroz. In: REUNIÃO DA CULTURA DO ARROZ IRRIGADO, 21., 1995, Porto Alegre, RS. Anais ... Porto Alegre: IRGA, 1995. p. 14-16.

MARCHEZAN, E., XAVIER, F. M., MICHELOTTI, L. Sistemas de preparo do solo e rotação de culturas no controle de arroz vermelho em várzea. In: REUNIÃO DA CULTURA DO ARROZ IRRIGADO, 21., 1995, Porto Alegre, RS. Anais ... Porto Alegre: IRGA, 1995. p.151-153.

MARCHEZAN, E., CIROLINI, F. Potencial de reinfestação do arroz vermelho. In: CONFERÊNCIA INTERNACIONAL DE ARROZ PARA A AMÉRICA LATINA E O CARIBE 19. e REUNIÃO NACIONAL DE PESQUISA DE ARROZ, 5., Goiânia, GO, Brasil, 1996. Arroz na América Latina: Perspectivas para o incremento da produção e do potencial produtivo. Goiânia, GO, Brasil, EMBRAPA-CNPAF, 1996, p. 198.

NOLDIN, J. A. Characterization, seed longevity, and herbicide sensitivity of red rice (Oryza sativa L) ecotypes, and red rice control in soybeans [Glycine $\max$ (L.) Merr.], $\mathrm{PhD}$ Dissertation, Texas A\&M University, 218p. 1995.

OLIVEIRA, J. C. S. de Sistema de cultivo do arroz irrigado no controle do arroz vermelho. Santa Maria: UFSM, 1993. 87p. Dissertação (Mestrado em Agronomia) Universidade Federal de Santa Maria, 1993.

PAUlETTO, E. A., TURATTI, A. L., GOMES, A. da S. et al. Produtividade do arroz irrigado em sistemas de cultivo mínimo e em rotação 
com soja e milho. In: REUNIÃO DA CULTURA DO ARROZ IRRIGADO, 1991, Camboriú, SC, Anais ... Camboriú:EMPASC, 1991, 350p, p.125-129.

PETRINI, J. A., FRANCO, D. F., GOMES, A. da S. Viabilidade de sementes de arroz vermelho (Oryza sativa L.) em função da submersão do solo em água e da profundidade de localização da semente. In: REUNIÃO DA CULTURA DO ARROZ IRRIGADO, 20. 1993, Anais ... Pelotas: EMBRAPA-CPACT, 1993a, 305p., p.283-286.

PETRINI, J. A., FRANCO, D. F., XAVIER, F. E. et al. Estudo preliminar do desempenho do sistema de semeadura de arroz pré-germinado no controle do arroz vermelho (Oryza sativa L.). 1992/93. In: REUNIÃO DA CULTURA DO ARROZ IRRIGADO, 20., 1993, Pelotas. Anais ... EMBRAPA-CPACT, 1993b, 305p., p.128-130.

PETRINI, J. A., XAVIER, F. E, SILVA, E. S. et al. Controle do arroz vermelho (Oryza sativa L.) no sistema de semeadura de arroz prégerminado. In: CONFERÊNCIA INTERNACIONAL DE ARROZ PARA A AMÉRICA LATINA E O CARIBE 19. e REUNIÃO NACIONAL DE PESQUISA DE ARROZ, 5., Goiânia, GO, Brasil, 1996. Arroz na América Latina: Perspectivas para o incremento da produção e do potencial produtivo. Goiânia, GO, Brasil, EMBRAPA-CNPAF, 1996, p.193.

PETRINI, J. A., FRANCO, D. F., TAVARES, W. Germinação e viabilidade de sementes de arroz vermelho (Oryza sativa L.) em solo cultivado com arroz irrigado no sistema convencional. In: REUNIÃO NACIONAL DE PESQUISA DE ARROZ. 6., 1998, Goiânia, GO. Perspectivas para a cultura do arroz nos ecossistemas de várzeas e terras baixas. Goiânia: EMBRAPA-CNPAF, 1998. 514p, p.373-376. (EMBRAPACNPAF. Documentos, 85).

ROBERTS, E. H. The effects of some organic growth substances and organic nutrients on dormancy in rice seed. Physiologia Plant., v.16, p.745-755, 1963.

ROBERTS, H. A., DAWKINS, P. A. Effect of cultivation on the number of viable weed seeds in soil. Weed Res., v.7, p.290-301, 1967.

ROTA, G. R. M. Efeitos da profundidade e inundações sobre 0 desempenho de sementes de arroz vermelho (Oryza sativa L.). Pelotas:UFPEL, 1983, 111p. Dissertação (Mestrado em Ciências Agrárias) - Curso de Tecnologia de Sementes, Universidade Federal de Pelotas, 1983.

SIKDER, H. P. Dormancy of paddy seeds in relation to different seed treatments. Exp. Agric. v.3, p.249-255, 1967.

SILVA, R. P. da, AVILA, L. A. de, ANDRES, A. et al. Banco de sementes de arroz vermelho em sistemas de semeadura de arroz irrigado (Oryza sativa L.). In: SALÃO DE INICIAÇÃO CIENTÍFICA 10., e FEIRA DE INICIAÇÃO CIENTÍFICA, 4., 1998, Porto Alegre. Livro de Resumos ... Porto Alegre: UFRGS, 1998, 503p, p.128.

SMITH, K. A., RESTALL, S. W. F. The occurrence of ethylene in anaerobic soil. $\mathbf{J}$. Soil Sci., v.22, n.4, p.430-443, 1971.

SMITH JR., R.J. Cropping and herbicide systems for red rice (Oryza sativa) control. Weed Tecnol., v.3, p.414-111419, 1989. 
SONNIER, E. A. Red rice control. In: RED RICE SYMPOSIUM HELD AT TEXAS A\&M UNIVERSITY, 1978, Texas. Procedings ... Texas, 1978.

SOUZA, P.R.; FISCHER, M.M. Arroz vermelho: danos causados à lavoura guaúcha. In:
REUNIÃO DA CULTURA DO ARROZ IRRIGADO, 15, 1986, Porto Alegre. Anais... Porto Alegre, IRGA 1986. p. 169-173.

TAYLORSON, R. B. Environmental and chemical manipulation of weed seed dormancy. Rev. Weed Sci., v.3, p.135-154, 1987. 